\title{
Pengaruh Self-Efficacy Pada Penerimaan E-Rapor SMP
}

\author{
Gunawan ${ }^{1}$, Muhammad Rizki Zulkarnain ${ }^{2}$ \\ ${ }^{1)}$ Peternakan, Universitas Kristen Palangka Raya, \\ Jl. J. P. Jandan No. 1, RTA Milono KM 8,5, Palangka Raya \\ ${ }^{2)}$ Pendidikan Teknologi Informasi, STKIP PGRI Banjarmasin, \\ Jl. Sultan Adam Kompleks H. Iyus No. 18 RT 23, Banjarmasin \\ Email: *1gunawan@tanak.unkrip.ac.id, ${ }^{2}$ rizkizulkarnain@ @tkipbjm.ac.id
}

\begin{abstract}
Abstrak
Penelitian ini dilakukan untuk menganalisis penerimaan e-Rapor SMP menggunakan Ekstensi Model Penerimaan Teknologi dengan menyertakan faktor Keyakinan-Sendiri (SelfEfficacy) di dalam model. Instrumen pengumpulan data berupa angket yang memuat 19 butir pernyataan serta menggunakan skala Likert 5. Responden pada penelitian ini adalah 60 orang pengguna e-Rapor di SMP Negeri di Banjarmasin. Data penelitian dianalisis menggunakan Partial Least Square-Structural Equation Model (PLS-SEM) pada aplikasi SmartPLS 3.3.2. Berdasarkan hasil penelitian diketahui bahwa Keyakinan-Sendiri (Self-Efficacy) mempengaruhi Minat Menggunakan e-Rapor secara signifikan dan positif.
\end{abstract}

Kata kunci-Ekstensi Model Penerimaan Teknologi, Keyakinan-Sendiri, Partial Least Square

\begin{abstract}
This research aims to analyze e-Rapor acceptance of junior high school using Extended Technology Acceptance Model (TAM) by including Self-Efficacy factor into the model. Data collection instrument in the form of questionnaire consisting of 19 points of statement and using 5 Point-Likert scale. The respondents were 60 e-Rapor users at public junior high school in Banjarmasin. The research data was analyzed using Partial Least Square-Structural Equation Modeling (PLS-SEM) with the assistance of SmartPLS 3.3.2 software. Based on the results of the study, it is known that Self-Efficacy has a directly positive and significant influence on the Behavioral Intention to use e-Rapor.
\end{abstract}

Keyword - Extended Technology Acceptance Model, Self-Efficacy, Partial Least Square

\section{PENDAHULUAN}

Evaluasi hasil belajar yang dilakukan oleh pendidik ialah bagian dari evaluasi pendidikan pada pendidikan tingkat menengah. Evaluasi hasil belajar dilakukan untuk mengukur serta mengenali pencapaian kompetensi siswa, memperbaiki proses pendidikan, serta menyusun laporan kemajuan hasil belajar setiap hari, tengah semester, akhir semester, akhir tahun, maupun kenaikan kelas. Prosedur evaluasi hasil belajar oleh pendidik dimulai dengan menetapkan tujuan evaluasi yang mengacu pada RPP yang sudah disusun, menyusun kisi- kisi evaluasi, membuat instrumen evaluasi serta pedoman evaluasi, melaksanakan evaluasi, mencerna, menganalisis serta menginterpretasikan hasil evaluasi, sampai memberi tahu hasil evaluasi serta menggunakan laporan hasil evaluasi [1]. Pelaporan hasil belajar siswa diyakini akan lebih cepat, lebihvakurat, serta lebih komprehensif bila didukung oleh perangkat komputer. Guna memfasilitasi hal tersebut, Direktorat Pembinaan Sekolah Menengah Pertama Kementerian 
Pendidikan dan Kebudayaan mengembangkan aplikasi e-Rapor SMP, beserta panduan penggunaannya. e-Rapor SMP yang diluncurkan pada November 2017 bisa disinkronisasikan ke Data Pokok Pendidikan dan sampai saat ini e-Rapor SMP sudah mengalami beberapa pembaruan dan versi terbaru yaitu e-Rapor SMP versi 2.2 baru saja diluncurkan pada November 2020 [2]. Kehadiran e-Rapor SMP ini diharapkan bisa membantu para pendidik dalam melaporkan hasil belajar peserta didik. Terlebih pada kondisi pandemi Covid-19 yang terjadi saat ini, keberadaan teknologi komputer dirasa sangat penting dan diperlukan untuk menopang kinerja pendidik, di antaranya dalam pelaporan hasil belajar siswa.

Dalam penerapannya, pendidik (guru) dihadapkan pada tantangan untuk sesegera mungkin bisa menguasai penggunaan e-Rapor SMP. Sebagian guru sudah memiliki kemampuan yang baik dalam mengoperasikan perangkat komputer karena memiliki pengalaman yang cukup dalam mengoperasikan perangkat komputer. Namun, sebagian yang lain tidak terlalu sering atau familiar dengan menggunakan perangkat komputer. Akibatnya, sebagian guru memerlukan waktu yang lebih lama dibanding yang lain untuk bisa menguasai cara menggunakannya, bahkan menyerah untuk mempelajari cara menggunakannya. Dikatakan bahwa tidak sedikit sistem teknologi informasi atau aplikasi yang gagal disebabkan oleh aspek teknisnya. Namun, meskipun kualitas dari sistem sudah membaik, ternyata masih banyak terdengar sistem teknologi informasi atau aplikasi yang gagal diterapkan. Berdasarkan penelitian-penelitian sebelumnya diketahui bahwa penyebab kegagalan suatu sistem teknologi informasi atau aplikasi adalah lebih pada aspek keprilakuannya (behavior). Masih sering terdengar bahwa suatu sistem teknologi informasi atau aplikasi gagal diterapkan secara berkelanjutan karena manusianya enggan atau tidak ingin menggunakannya dengan berbagai alibi [3]. Oleh sebab itu, dibutuhkan suatu penelitian untuk mengetahui dan menganalisis faktor-faktor yang mungkin mempengaruhi penerimaan guru dalam menggunakan e-Rapor SMP. Dalam penelitian ini, peneliti menyertakan faktor Keyakinan-Sendiri (Self-Efficacy) dalam analisis penerimaan pengguna e-Rapor.

\section{METODE PENELITIAN}

\subsection{Extended Technology Acceptance Model (Extended TAM)}

TAM adalah suatu model penerimaan sistem teknologi informasi yang dikembangkan oleh Davis et al (1989) yang terinspirasi dari model TRA. Model TRA bisa diterapkan sebab keputusan-keputusan yang kerap dilakukan oleh seseorang untuk menerima suatu sistem teknologi informasi adalah aksi sadar yang bisa diuraikan serta diprediksi dari minat perilakunya. Pada TAM, ada dua konstruk utama yang ditambahkan ke dalam model TRA. Dua konstruk tersebut adalah konstruk kegunaan persepsian (perceived usefulness) dan konstruk kemudahan penggunaan persepsian (perceived ease of use). TAM berpendapat bahwa penerimaan seseorang terhadap suatu sistem teknologi informasi merujuk pada dua konstruk tersebut. TAM adalah suatu model perilaku (behavior) yang memiliki manfaat untuk mengetahui jawaban dari pertanyaan mengapa tidak sedikit sistem teknologi informasi atau aplikasi yang gagal diterapkan (yang diantaranya disebabkan oleh penggunanya tidak mempunyai ketertarikan atau minat (intention) untuk menggunakan suatu sistem teknologi informasi atau aplikasi). Pada TAM mula-mula, terdapat empat konstruk, yaitu kegunaan persepsian (perceived usefulness), kemudahan penggunaan persepsian (perceived ease of use), minat perilaku (behavioral intention), dan perilaku (behavior). Namun hingga kini, banyak peneliti berupaya mengembangkan (mengekstensi) TAM dengan menyertakan konstrukkonstruk eksternal [3].

Pada analisis penerimaan e-Rapor dalam penelitian ini digunakan Ekstensi Model Penerimaan Teknologi atau Extended Technology Acceptance Model (Extended TAM) dengan menyertakan konstruk Keyakinan-Sendiri (Self-Efficacy) pada model. Secara lengkap, konstrukkonstruk yang digunakan pada model adalah: 
a. Self-Efficacy (SE) atau Keyakinan-Sendiri, yaitu keyakinan seseorang mengenai kemampuannya untuk melakukan suatu tindakan atau perilaku tertentu;

b. Perceived Ease of Use (PEOU) atau Kemudahan Penggunaan Persepsian, yaitu persepsi seseorang dalam meyakini bahwa suatu teknologi akan mudah untuk digunakan;

c. Perceived Usefulnes (PU) atau Kegunaan Persepsian, yaitu persepsi seseorang dalam meyakini bahwa teknologi yang digunakan memberikan manfaat dan meningkatkan kinerjanya;

d. Attitude towards Using Technology (ATU) atau Sikap Menggunakan Teknologi, yaitu perasaan positif atau negatif seseorang apabila harus melakukan suatu tindakan atau perilaku tertentu;

e. Behavioral Intention to Use (BI) atau Minat Perilaku Menggunakan Teknologi, yaitu suatu minat atau keinginan seseorang untuk melakukan suatu tindakan atau perilaku tertentu [3].

\subsection{Metode dan Instrumen (Alat) Pengumpulan Data}

Pengumpulan data dilakukan dengan menggunakan teknik angket atau kuesioner. Pengumpulan data pada penelitian ini menggunakan instrumen (alat) berupa lembar angket yang memuat 19 butir pernyataan yang masing-masing memiliki lima pilihan respons atau jawaban (menggunakan skala Likert 5). Berikut daftar pernyataan yang digunakan pada angket.

Tabel 1. Instrumen Angket

\begin{tabular}{|c|c|c|}
\hline Konstruk & Indikator/ Pernyataan & Simbol \\
\hline \multirow{4}{*}{$\begin{array}{l}\text { Kemudahan } \\
\text { Penggunaan } \\
\text { Persepsian (Perceived } \\
\text { Ease of Use/ PEOU) }\end{array}$} & $\begin{array}{l}\text { Mudah bagi saya untuk mempelajari cara menggunakan } \\
\text { e-Rapor. }\end{array}$ & PEOU1 \\
\hline & $\begin{array}{l}\text { Mudah bagi saya untuk melakukan apa yang saya ingin } \\
\text { lakukan pada e-Rapor. }\end{array}$ & PEOU2 \\
\hline & $\begin{array}{l}\text { Mudah bagi saya untuk menjadi terampil dalam } \\
\text { menggunakan e-Rapor. }\end{array}$ & PEOU3 \\
\hline & e-Rapor mudah untuk digunakan. & PEOU4 \\
\hline \multirow{4}{*}{$\begin{array}{l}\text { Kegunaan Persepsian } \\
\text { (Perceived Usefulnes/ } \\
\text { PU) }\end{array}$} & $\begin{array}{l}\text { Menggunakan e-Rapor memungkinkan saya } \\
\text { menyelesaikan pekerjaan dengan lebih cepat. }\end{array}$ & PU1 \\
\hline & Menggunakan e-Rapor meningkatkan kinerja saya. & PU2 \\
\hline & Menggunakan e-Rapor mempermudah pekerjaan saya. & PU3 \\
\hline & e-Rapor bermanfaat bagi saya. & PU4 \\
\hline \multirow{4}{*}{$\begin{array}{l}\text { Sikap Menggunakan } \\
\text { Teknologi (Attitude } \\
\text { towards Using } \\
\text { Technology/ ATU) }\end{array}$} & Menggunakan e-Rapor merupakan ide yang bagus. & ATU1 \\
\hline & $\begin{array}{l}\text { Menggunakan e-Rapor merupakan tindakan yang } \\
\text { bijaksana. }\end{array}$ & ATU2 \\
\hline & e-Rapor membuat pekerjaan menjadi lebih menarik. & ATU3 \\
\hline & Bekerja dengan e-Rapor itu menyenangkan. & ATU4 \\
\hline \multirow{2}{*}{$\begin{array}{l}\text { Minat Perilaku } \\
\text { Menggunakan } \\
\text { Teknologi (Behavioral } \\
\text { Intention to Use/ BI) }\end{array}$} & $\begin{array}{l}\text { Saya memperkirakan saya akan tetap menggunakan e- } \\
\text { Rapor dalam } 12 \text { bulan ke depan. }\end{array}$ & BI1 \\
\hline & Saya berharap untuk terus menggunakan e-Rapor. & $\mathrm{BI} 2$ \\
\hline \multirow[t]{3}{*}{$\begin{array}{l}\text { Keyakinan-Sendiri } \\
\text { (Self-Efficacy/SE) }\end{array}$} & $\begin{array}{l}\text { Saya yakin mampu memecahkan masalah yang sulit } \\
\text { terkait penggunaan e-Rapor jika saya berusaha cukup } \\
\text { keras. }\end{array}$ & SE1 \\
\hline & $\begin{array}{l}\text { Saya tetap tenang ketika menghadapi kesulitan dalam } \\
\text { menggunakan e-Rapor. }\end{array}$ & SE2 \\
\hline & $\begin{array}{l}\text { Ketika saya dihadapkan dengan masalah dalam } \\
\text { menggunakan e-Rapor, saya biasanya dapat }\end{array}$ & SE3 \\
\hline
\end{tabular}




\begin{tabular}{|l|l|c|}
\hline Konstruk & \multicolumn{1}{|c|}{ Indikator/ Pernyataan } & Simbol \\
\hline & menemukan beberapa solusi. & SE4 \\
\cline { 2 - 3 } & $\begin{array}{l}\text { Saya yakin mampu menyelesaikan pekerjaan saya } \\
\text { dengan e-Rapor dengan mengikuti petunjuk } \\
\text { penggunaan e-Rapor. }\end{array}$ & SE5 \\
\cline { 2 - 3 } & $\begin{array}{l}\text { Saya yakin mampu menyelesaikan pekerjaan saya } \\
\text { dengan e-Rapor setelah seseorang menunjukkan cara } \\
\text { penggunaan e-Rapor kepada saya. }\end{array}$ & \\
\hline
\end{tabular}

Sumber: Diadaptasi dari [4]-[7]

\subsection{Teknik Analisis Data}

Data pada penelitian ini dianalisis dengan Partial Least Square-Structural Equation Modeling (PLS-SEM) dan menggunakan aplikasi SmartPLS versi 3.3.2. PLS-SEM bisa diterapkan pada jumlah sampel yang tidak besar maupun data yang tidak berdistribusi normal [8]. Berikut tahapan-tahapan Partial Least Square-Structural Equation Modeling (PLS-SEM) yang dilakukan $[8]$ :

1. Spesifikasi Model;

Model pada penelitian ini adalah model refleksif yang melibatkan 5 konstruk dan 19 indikator. Berikut model yang digunakan peneliti.

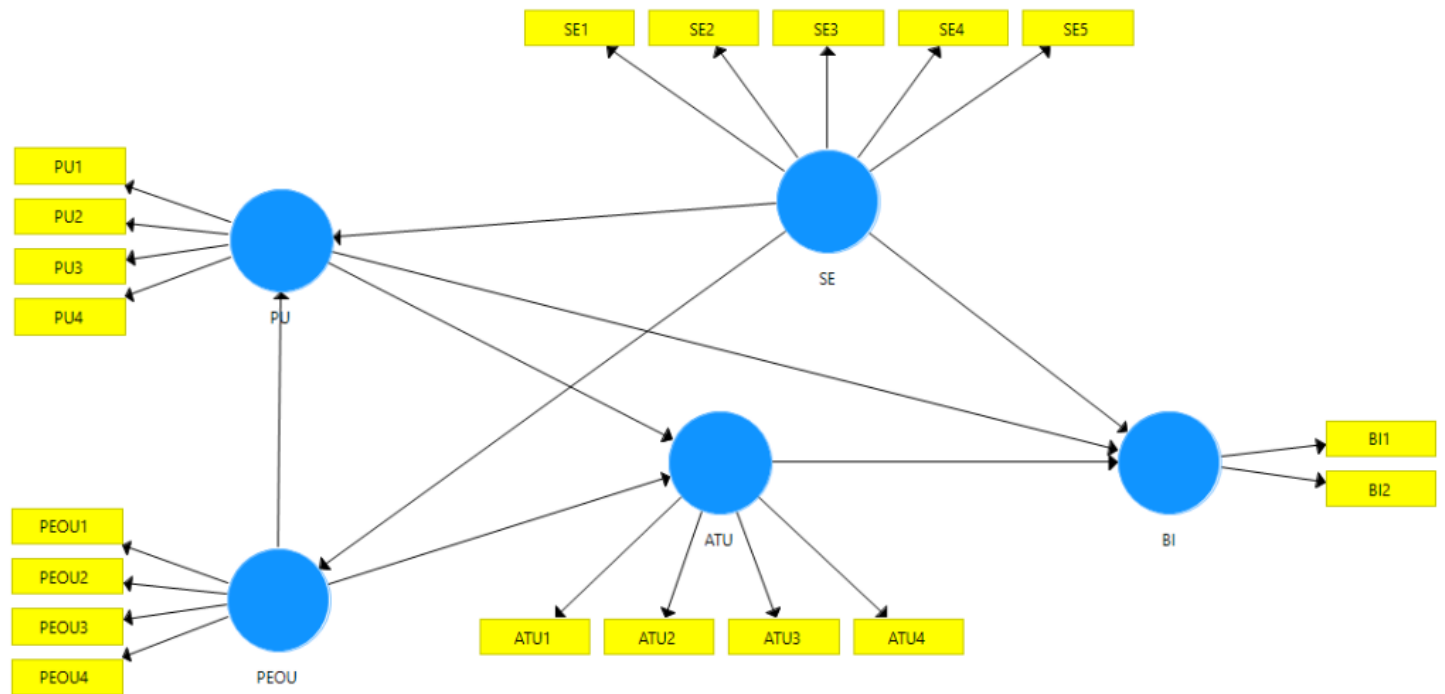

Gambar 1. Model yang Diteliti [9]

2. Evaluasi Outer Model atau Measurement Model (Model Pengukuran);

Pada tahapan Evaluasi Outer Model atau Measurement Model (Model Pengukuran), kriteria-kriteria yang perlu diperhatikan adalah:

a. Indicator reliability;

b. Internal consistency reliability;

c. Convergent validity (Validitas konvergen);

d. Discriminant validity (Validitas diskriminan) [10].

3. Evaluasi Inner Model atau Structural Model (Model Struktural).

Pada tahapan Evaluasi Inner Model atau Structural Model (Model Struktural), bisa diketahui mengenai:

a. Nilai koefisien determinasi atau $R^{2}$ dari konstruk endogen; 
b. Signifikansi koefisien jalur [10].

\subsection{Responden}

Responden pada penelitian ini terdiri dari 60 orang pengguna e-Rapor SMP yang bekerja di SMPN 5 Banjarmasin, SMPN 23 Banjarmasin, dan SMPN 34 Banjarmasin.

\section{HASIL DAN PEMBAHASAN}

Algoritma PLS (estimasi) pertama belum menunjukkan hasil yang baik, sehingga ada indikator yang perlu dihilangkan dari model, yaitu indikator PEOU4 dan PU3. Akibatnya, dilakukan perhitungan (estimasi) yang kedua.

\subsection{Evaluasi Outer Model atau Measurement Model (Model Pengukuran)}

Hasil pengolahan data dengan menggunakan aplikasi SmartPLS 3.3.2 yang menunjukkan indicator reliability bisa dilihat pada Tabel 2 berikut.

Tabel 2. Nilai Loading dan Indicator Reliability

\begin{tabular}{|c|c|c|}
\hline Indikator & $\begin{array}{c}\text { Indicator (Outer) } \\
\text { Loading }\end{array}$ & $\begin{array}{c}\text { Indicator } \\
\text { Reliability }\end{array}$ \\
\hline ATU1 & 0,881 & 0,776 \\
\hline ATU2 & 0,847 & 0,718 \\
\hline ATU3 & 0,910 & 0,829 \\
\hline ATU4 & 0,929 & 0,863 \\
\hline BI1 & 0,942 & 0,887 \\
\hline BI2 & 0,957 & 0,917 \\
\hline PEOU1 & 0,876 & 0,768 \\
\hline PEOU2 & 0,771 & 0,594 \\
\hline PEOU3 & 0,879 & 0,772 \\
\hline PU1 & 0,888 & 0,789 \\
\hline PU2 & 0,899 & 0,809 \\
\hline PU4 & 0,919 & 0,844 \\
\hline SE1 & 0,847 & 0,718 \\
\hline SE2 & 0,881 & 0,776 \\
\hline SE3 & 0,908 & 0,825 \\
\hline SE4 & 0,834 & 0,695 \\
\hline SE5 & 0,800 & 0,639 \\
\hline
\end{tabular}

Sumber: Data olahan dari SmartPLS Tahun 2020 [9]

Suatu indikator dengan nilai loading lebih dari 0,708 (atau setara dengan nilai indicator reliability lebih dari 0,5) memiliki reliabilitas yang baik [11]. Berdasarkan Tabel 2 bisa diketahui bahwa setiap indikator yang ada sudah memiliki reliabilitas yang baik.

Selanjutnya, internal consistency reliability suatu konstruk ditunjukkan oleh nilai Cronbach's $\alpha, \rho_{A}$, dan Composite Reliability $\left(\rho_{c}\right)$ masing-masing konstruk, disajikan pada Tabel 3 berikut. 
Tabel 3. Nilai Cronbach's $\alpha, \rho_{A}$, dan Composite Reliability $\left(\rho_{c}\right)$

\begin{tabular}{|c|c|c|c|}
\hline Konstruk & $\begin{array}{c}\text { Cronbach's } \\
\alpha\end{array}$ & $\rho_{A}$ & $\begin{array}{c}\text { Composite } \\
\text { Reliability } \\
\left(\rho_{c}\right)\end{array}$ \\
\hline ATU & 0,914 & 0,916 & 0,940 \\
\hline BI & 0,892 & 0,907 & 0,948 \\
\hline PEOU & 0,797 & 0,814 & 0,881 \\
\hline PU & 0,886 & 0,889 & 0,929 \\
\hline SE & 0,907 & 0,908 & 0,931 \\
\hline
\end{tabular}

Sumber: Data Olahan dari SmartPLS Tahun 2020 [9]

Suatu konstruk dengan nilai Cronbach's $\alpha$ sebesar 0,70 hingga 0,90 , nilai $\rho_{A}$ di atas 0,70 , dan nilai $\rho_{c}$ sebesar 0,70 hingga 0,95 menunjukkan internal consistency reliability yang baik [10]. Berdasarkan Tabel 3 di atas bisa diketahui bahwa setiap konstruk sudah memiliki internal consistency reliability yang baik.

Selanjutnya, validitas konvergen suatu konstruk bisa diketahui melalui nilai Average Variance Extracted (AVE) untuk setiap konstruk, ditunjukkan pada Tabel 4 berikut.

Tabel 4. Nilai AVE

\begin{tabular}{|c|c|}
\hline Konstruk & AVE \\
\hline ATU & 0,796 \\
\hline BI & 0,902 \\
\hline PEOU & 0,711 \\
\hline PU & 0,814 \\
\hline SN & 0,731 \\
\hline
\end{tabular}

Sumber: Data Olahan dari

SmartPLS Tahun 2020 [9]

Suatu konstruk dengan nilai AVE 0,50 atau lebih menunjukkan validitas konvergen yang baik [10]. Berdasarkan nilai AVE pada Tabel 4 bisa diketahui bahwa setiap konstruk sudah memiliki validitas konvergen yang baik.

Selanjutnya, validitas diskriminan bisa dilihat dari nilai Cross Loadings, Kriteria FornellLarcker, dan Heterotrait-Monotrait Ratio (HTMT), masing-masing disajikan pada Tabel 5, Tabel 6, dan Tabel 7 berikut.

Tabel 5. Cross Loadings

\begin{tabular}{|c|c|c|c|c|c|}
\hline & ATU & BI & PEOU & PU & SE \\
\hline ATU1 & 0,881 & 0,596 & 0,454 & 0,662 & 0,671 \\
\hline ATU2 & 0,847 & 0,506 & 0,616 & 0,593 & 0,551 \\
\hline ATU3 & 0,910 & 0,512 & 0,574 & 0,729 & 0,578 \\
\hline ATU4 & 0,929 & 0,458 & 0,583 & 0,734 & 0,613 \\
\hline BI1 & 0,455 & 0,942 & 0,309 & 0,222 & 0,504 \\
\hline BI2 & 0,635 & 0,957 & 0,454 & 0,423 & 0,549 \\
\hline PEOU1 & 0,578 & 0,419 & 0,876 & 0,666 & 0,518 \\
\hline PEOU2 & 0,500 & 0,355 & 0,771 & 0,459 & 0,396 \\
\hline PEOU3 & 0,496 & 0,260 & 0,879 & 0,639 & 0,563 \\
\hline PU1 & 0,667 & 0,227 & 0,635 & 0,888 & 0,460 \\
\hline PU2 & 0,660 & 0,332 & 0,645 & 0,899 & 0,561 \\
\hline PU4 & 0,736 & 0,375 & 0,631 & 0,919 & 0,552 \\
\hline SE1 & 0,540 & 0,366 & 0,519 & 0,488 & 0,847 \\
\hline
\end{tabular}




\begin{tabular}{|c|c|c|c|c|c|}
\hline & ATU & BI & PEOU & PU & SE \\
\hline SE2 & 0,537 & 0,438 & 0,504 & 0,487 & 0,881 \\
\hline SE3 & 0,521 & 0,512 & 0,465 & 0,464 & 0,908 \\
\hline SE4 & 0,614 & 0,553 & 0,555 & 0,511 & 0,834 \\
\hline SE5 & 0,665 & 0,488 & 0,468 & 0,532 & 0,800 \\
\hline
\end{tabular}

(Sumber: Data Olahan dari SmartPLS Tahun 2020 [9]

Pada Tabel 5 bisa dilihat bahwa indicator loading untuk setiap indikator pada konstruk yang diukur memiliki nilai yang lebih tinggi daripada nilai indicator loading yang digunakan untuk mengukur konstruk lain.

Tabel 6 Kriteria Fornell-Larcker

\begin{tabular}{|c|c|c|c|c|c|}
\hline & ATU & BI & PEOU & PU & SE \\
\hline ATU & 0,892 & & & & \\
\hline BI & 0,581 & 0,950 & & & \\
\hline PEOU & 0,622 & 0,407 & 0,843 & & \\
\hline PU & 0,763 & 0,348 & 0,706 & 0,902 & \\
\hline SE & 0,677 & 0,556 & 0,590 & 0,583 & 0,855 \\
\hline
\end{tabular}

Sumber: Data Plahan dari SmartPLS Tahun 2020 [9]

*nilai pada diagonal utama (bagian yang diberi warna abu-abu) merupakan akar kuadrat dari AVE

Pada masing-masing konstruk, jika akar kuadrat AVE bernilai lebih dari nilai korelasi antara konstruk tersebut dengan konstruk lain, maka konstruk tersebut memiliki discriminant validity (validitas diskriminan) yang baik [8]. Berdasarkan Tabel 6 di atas bisa diketahui bahwa setiap konstruk sudah memiliki validitas diskriminan yang baik.

Tabel 7 Heterotrait-Monotrait Ratio (HTMT)

\begin{tabular}{|c|c|c|c|c|c|}
\hline & ATU & BI & PEOU & PU & SN \\
\hline ATU & & & & & \\
\hline BI & 0,635 & & & & \\
\hline PEOU & 0,732 & 0,479 & & & \\
\hline PU & 0,845 & 0,379 & 0,830 & & \\
\hline SE & 0,739 & 0,612 & 0,685 & 0,646 & \\
\hline
\end{tabular}

Sumber: Data Olahan dari SmartPLS Tahun 2020 [9]

Nilai HTMT kurang dari 0,85 menunjukkan validitas diskriminan yang baik [12]. Berdasarkan nilai HTMT pada Tabel 7 di atas bisa diketahui bahwa setiap konstruk sudah memiliki validitas diskriminan yang baik.

\subsection{Evaluasi Inner Model (Structural Model atau Model Struktural)} berikut.

Nilai koefisien determinasi atau $\mathrm{R}^{2}$ untuk konstruk endogen bisa dilihat pada Tabel 8 
Tabel 8. Nilai $\mathrm{R}^{2}$

\begin{tabular}{|c|c|}
\hline Konstruk & $\mathrm{R}^{2}$ \\
\hline ATU & 0,596 \\
\hline BI & 0,419 \\
\hline PEOU & 0,348 \\
\hline PU & 0,541 \\
\hline
\end{tabular}

Sumber: Data Olahan dari

SmartPLS Tahun 2020 [9]

Berdasarkan nilai $\mathrm{R}^{2}$ pada Tabel 8 di atas bisa diketahui bahwa (a) Konstruk PU dan PEOU mampu menjelaskan konstruk ATU sebesar 59,6\%, (b) Konstruk SE, PU, dan ATU menjelaskan konstruk BI sebesar 41,9\%, (c) Konstruk SE mampu menjelaskan konstruk PEOU sebesar 34,8\%, dan (d) Konstruk SN dan PEOU mampu menjelaskan konstruk PU sebesar 54,1\%.

Selanjutnya dilakukan prosedur bootstraping (resampling menjadi 500 subsampel) dan melakukan pengujian satu arah dengan taraf signifikansi 5\%. Hasil pengujian bisa dilihat pada Tabel 9 berikut.

Tabel 9. Signifikansi Koefisien Jalur

\begin{tabular}{|c|c|c|c|c|c|}
\hline & $\begin{array}{c}\text { Sampel } \\
\text { Asli (O) }\end{array}$ & $\begin{array}{c}\text { Rata-rata } \\
\text { Sampel (M) }\end{array}$ & $\begin{array}{c}\text { Standar Deviasi } \\
(\text { STDEV })\end{array}$ & $\begin{array}{c}\text { T Statistik } \\
(\mid \text { O/STDEV } \mid)\end{array}$ & Nilai P \\
\hline $\mathrm{SE} \rightarrow$ PU & 0,255 & 0,261 & 0,118 & 2,165 & 0,015 \\
\hline $\mathrm{SE} \rightarrow$ PEOU & 0,590 & 0,598 & 0,078 & 7,514 & 0,000 \\
\hline $\mathrm{SE} \rightarrow \mathrm{BI}$ & 0,335 & 0,338 & 0,160 & 2,089 & 0,019 \\
\hline $\mathrm{PU} \rightarrow \mathrm{BI}$ & $-0,281$ & $-0,301$ & 0,180 & 1,562 & 0,060 \\
\hline $\mathrm{PU} \rightarrow$ ATU & 0,645 & 0,642 & 0,109 & 5,901 & 0,000 \\
\hline $\mathrm{PEOU} \rightarrow \mathrm{PU}$ & 0,555 & 0,551 & 0,122 & 4,555 & 0,000 \\
\hline $\mathrm{PEOU} \rightarrow \mathrm{ATU}$ & 0,167 & 0,169 & 0,135 & 1,238 & 0,108 \\
\hline $\mathrm{ATU} \rightarrow \mathrm{BI}$ & 0,569 & 0,589 & 0,194 & 2,938 & 0,002 \\
\hline
\end{tabular}

Sumber: Data Olahan dari SmartPLS Tahun 2020 [9]

Dari Tabel 9 di atas bisa dilihat bahwa

1. Konstruk SE berpengaruh signifikan dan positif terhadap konstruk PU, dilihat dari P yang bernilai 0,015 (di bawah 0,05) dan sampel asli (O) yang bernilai positif, yaitu 0,255.

2. Konstruk SE berpengaruh signifikan dan positif terhadap konstruk PEOU, dilihat dari $\mathrm{P}$ yang bernilai 0,000 (di bawah 0,05) dan sampel asli (O) yang bernilai positif, yaitu 0,590.

3. Konstruk SE berpengaruh signifikan dan positif terhadap konstruk BI, dilihat dari P yang bernilai 0,019 (di bawah 0,05 ) dan sampel asli $(\mathrm{O})$ yang bernilai positif, yaitu 0,335.

4. Konstruk PU tidak berpengaruh signifikan terhadap konstruk BI, dilihat dari P yang bernilai 0,060 (di atas 0,05).

5. Konstruk PU berpengaruh signifikan dan positif terhadap konstruk ATU, dilihat dari P yang bernilai 0,000 (di bawah 0,05 ) dan sampel asli $(\mathrm{O})$ yang bernilai positif, yaitu 0,645 .

6. Konstruk PEOU berpengaruh signifikan dan positif terhadap konstruk PU, dilihat dari $P$ yang bernilai 0,000 (di bawah 0,05 ) dan sampel asli $(O)$ yang bernilai positif, yaitu 0,555.

7. Konstruk PEOU tidak berpengaruh signifikan terhadap konstruk ATU, dilihat dari P yang bernilai 0,108 (di atas 0,05 ).

8. Konstruk ATU berpengaruh signifikan dan positif terhadap konstruk BI, dilihat dari $\mathrm{P}$ yang bernilai 0,002 (di bawah 0,05 ) dan sampel asli $(\mathrm{O})$ yang bernilai positif, yaitu 0,569. 


\section{KESIMPULAN}

Berdasarkan hasil penelitian di atas, bisa disimpulkan bahwa Sikap Menggunakan Teknologi (Attitude Toward Using Technology) berpengaruh signifikan dan positif terhadap Minat Menggunakan Teknologi (Behavioral Intention to Use). Hal ini berarti perasaan (affect) positif atau negatif seseorang apabila harus menggunakan e-Rapor mempengaruhi keinginan atau minatnya untuk menggunakan e-Rapor. Meningkatkan atau menurunkan perasaan positif atau negatif seseorang apabila harus menggunakan e-Rapor akan meningkatkan atau menurunkan minatnya untuk menggunakan e-Rapor. Selain itu, Keyakinan-Sendiri (SelfEfficacy) berpengaruh signifikan dan positif terhadap Minat Menggunakan Teknologi (Behavioral Intention to Use). Hal ini berarti keyakinan seseorang mengenai kemampuannya untuk melakukan suatu tindakan atau perilaku yang berhubungan dengan penggunaan komputer mempengaruhi keinginan atau minatnya untuk menggunakan e-Rapor. Meningkatkan atau menurunkan keyakinan diri seseorang terkait penggunaan komputer akan meningkatkan atau menurunkan minatnya untuk menggunakan e-Rapor.

\section{SARAN}

Berdasarkan hasil penelitian dan kesimpulan yang sudah dihasilkan, peneliti menyarankan perlunya peran aktif berbagai pihak untuk meningkatkan minat calon pengguna maupun pengguna e-Rapor untuk menggunakan e-Rapor, di antaranya dengan meningkatkan perasaan positif dari seseorang terhadap penggunaan e-Rapor dan meningkatkan kepercayaan diri calon pengguna e-Rapor terkait penggunaan komputer. Hal tersebut bisa diupayakan dengan memberikan pelatihan dan pendampingan secara intensif mengenai penggunaan e-Rapor. Peneliti juga berharap hasil penelitian ini bisa menjadi referensi dan memberikan masukan bagi penelitian selanjutnya terkait analisis penerimaan e-Rapor dengan menyertakan faktor-faktor lain yang mungkin mempengaruhi minat menggunakan e-Rapor.

\section{UCAPAN TERIMA KASIH}

Tim peneliti mengucapkan terima kasih yang sebesar-besarnya atas dukungan semua pihak yang terlibat, di antaranya

1. Direktorat Riset dan Pengabdian Masyarakat (DRPM), Kementerian Riset dan Teknologi/ Badan Riset dan Inovasi Nasional.

2. Dinas Pendidikan Kota Banjarmasin.

3. SMPN Se-Kota Banjarmasin, khususnya SMPN 5, SMPN 23, dan SMPN 34 Banjarmasin.

\section{DAFTAR PUSTAKA}

[1] Republik Indonesia. 2016, "Peraturan Menteri Pendidikan dan Kebudayaan Republik Indonesia Nomor 23 Tahun 2016 Tentang Standar Penilaian Pendidikan," https://bsnpindonesia.org/wp-content/uploads/2009/09/Permendikbud_Tahun2016_Nomor023.pdf (accessed Dec. 08, 2020).

[2] Mulyatsyah, 2020. "Kata Sambutan," http://ditsmp.kemdikbud.go.id/erapor/ (Accessed Feb. 16, 2021). 
[3] J. Hartono. 2007, Sistem Informasi Keperilakuan, Andi, Yogyakarta

[4] Q. Ma and L. Liu. 2004, "The Technology Acceptance Model: A Meta-Analysis of Empirical Findings,” J. Organ. End User Comput., Vol. 16, No. 1, pp. 59-72, doi: 10.4018/978-1-59140-474-3.ch006.

[5] V. Venkatesh, M. G. Morris, G. B. Davis, and F. D. Davis. 2003, "User Acceptance of Information Information Technology: Toward A Unified View, ” MIS Q., Vol. 27, No. 3, pp. 425-478, doi: https://doi.org/10.2307/30036540.

[6] F. D. Davis. 1989, "Perceived Usefulness, Perceived Ease of Use, and User Acceptance of Information Technology," MIS Q., Vol. 13, No. 3, pp. 319-340, doi: https://doi.org/10.2307/249008.

[7] F. D. Davis, R. P. Bagozzi, and P. R. Warshaw. 1989, "User Acceptance of Computer Technology: A Comparison of Two Theoritical Models," Manage. Sci., Vol. 35, No. 8, pp. 982-1003, doi: https://doi.org/10.1287/mnsc.35.8.982.

[8] J. F. Hair, M. Sarstedt, L. Hopkins, and V. G. Kuppelwieser. 2014, "Partial Least Squares Structural Equation Modeling (PLS-SEM), An Emerging Tool Ini Business Research," Eur. Bus. Rev., Vol. 26, No. 2, pp. 106-121.

[9] C. M. Ringle, S. Wende, and J. M. Becker. 2015, “SmartPLS 3." Boenningstedt: SmartPLS GmbH, [Online]. Available: http://www.smartpls.com.

[10] M. Sarstedt, C. M. Ringle, and J. F. Hair. 2017, "Partial Least Squares Structural Equation Modeling," in Handbook of Market Research, C. Homburg, M. Klarmann, and A. E. Vomberg, Eds. Cham: Springer International Publishing.

[11] C. Kalinzi. 2019, “What Does Indicator's Reliability Indicate in PLS SEM Specially In Smart PLS Results?," https://www.researchgate.net/post/What-does-indicatorsreliability-indicate-in-PLS-SEM-specially-in-smart-PLSresults/5dc18383aa1f0950d904d4a2/citation/download.

[12] J. Henseler, C. M. Ringle, and M. Sarstedt. 2015, "A New Criterion for Assessing Discriminant Validity In Variance-Based Structural Equation Modeling, ” J. Acad. Mark. Sci., Vol. 43, No. 1, pp. 115-135, doi: 10.1007/s11747-014-0403-8. 